\title{
Review of: "Biocultural key species: an assembly of biotic resources with biocultural importance"
}

\author{
Alejandra González-Moreno ${ }^{1}$ \\ 1 Conkal Institute of Technology
}

Potential competing interests: The author(s) declared that no potential competing interests exist.

This Ms. is very interesting and important to identifying species with biological and cultural importance that be used to conservation. This kind of indices is useful for a better interpretation of the relevance of fauna and flora for the communities. All Ms. is well redacted and organized with concordance between aim, methods, results and conclusion.

Abstract described all parts of Ms. The background contain a revision according to the developed theme. Methods are explained very clearly, the variables choosing for integrating the BKSI index reflect the importance for the Nahua people, regardless of the biological species richness for each taxon. Results, discussion and conclusion are adequate.

I recommended publishing this article but it is necessary to attend before this minor revision:

Minor revision:

Abstract, in Methods add Country where the study was realized: (Mexico).

In Results: Missing coma in last line: "with 1436 mentions"

Table 3: You could change "Fishes" for River fauna. Orden Insectivora? Ratón?

“Graminae" changed into Poaceae. This table must be re organized as well: Groups (plants, fungi, mammals, birds) and in each one, must be organized by order and family, or only family, I mean, if you use “Orden" like Chiroptera, all table must considered this classification (order) for every family.

Pag. 43, line 6: "when the values are weighted. which corresponds..."the dot must be changed by comma 